\title{
DERECHO PROCESAL TRANSFORMADOR EN LA REPARACIÓN DE LAS NUEVAS VÍCTIMAS DEL CONFLICTO ARMADO EN COLOMBIA: DESAFÍOS PARA EL PROCESO DE RESPONSABILIDAD DEL ESTADO
}

\author{
TRANSFORMATIVE PROCEDURAL LAW IN THE REPARATION OF \\ THE NEW VICTIMS OF THE ARMED CONFLICT IN COLOMBIA: \\ CHALLENGES FOR THE STATE LIABILITY PROCEEDINGS
}

\author{
Diego Armando Yánez Meza* \\ Jessica Tatiana Jiménez Escalante
}

\begin{abstract}
RESUMEN: El proceso de responsabilidad del Estado y el sistema de acciones que permiten tramitar la pretensión de responsabilidad del Estado ante el juez contencioso administrativo, se caracterizan por una forma poco adaptada para la realidad de las víctimas, que no garantiza con tutela efectiva y plazos razonables, el derecho fundamental a la reparación integral. Bajo esta hipótesis se cuestiona sobre la necesidad de la configuración de un derecho procesal transformador a través de la búsqueda y adecuación de nuevos procedimientos antes inexistentes, que les responda a las tragedias de las víctimas del conflicto armado en Colombia, aun en el escenario de los acuerdos de paz y el posconflicto, donde la magnitud de las víctimas persiste. Esta alternativa podría configurarse desde la jurisprudencia y el procedimiento administrativo creado para hacer decir a la administración pública las palabras del juez, a través de la extensión de los efectos a situaciones que tengan los mismos supuestos fácticos y jurídicos, es decir, el procedimiento administrativo especial de extensión de la jurisprudencia del Consejo de Estado a terceros.
\end{abstract}

Palabras clave: Reparación, procedimiento, jurisprudencia, víctimas.

ABSTRACT: The proceedings for establishing the responsibility of the State are not adapted for the reality of the victims. They do not guarantee-effectively and within a reasonable period- the fundamental right to a full reparation. In light of this statement, this paper enquires about the necessity of establishing a transformative procedural law through the use of new

\footnotetext{
* Abogado, Universidad Libre, Cúcuta. Magíster en Derecho Administrativo (Investigativa), Universidad Externado de Colombia. Dirección electrónica: diego.yanez@unilibre.edu.co; diegoymezabogado@gmail.com. Este documento es resultado del proyecto de investigación "Criterios de aplicabilidad del Procedimiento administrativo especial de extensión de la jurisprudencia del Consejo de Estado en Colombia: un estudio comparado a partir de la experiencia española" desarrollado por el Semillero de Investigación en Derecho Administrativo "Louis Antoine Macarel" de la Universidad Libre, Cúcuta, Colombia, adscrito a la línea de investigación "Conocimiento, innovación y desarrollo sostenible regional", sublínea "Justicia, derecho procesal y sistema penal acusatorio". Actuaron como integrantes del Semillero de Investigación los estudiantes Paula Andrea Llanes Méndez, Jesús David Reyes Granados, Valery Vanessa Cacua Delgado, Kevin Daniel Arce Hernández, Nora Alejandra Mejía Antolinez, Yurley Andrea Vanegas López, Wendy Daniela Taborda Pedrozo, Paula Valentina Hernández Pedrozo; Jhocyo Ranssay Verano Castillo.

** Abogado, Universidad Libre, Cúcuta. Integrante del Semillero de Investigación en Derecho Administrativo “Louis Antonie Macarel”. Correo electrónico: jessica.jimenez@unilibrecucuta.edu.co; jessica.tatiana@hotmail.com.
} 
proceedings that may grant reparations to the victims of the Colombian armed conflict, even within the context of the Peace Agreements and the post-conflict, where the magnitude of the number of victims is relevant. This necessity could be satisfied by using case law and the special administrative proceeding for extending the State Council's case law to third parties (an administrative procedure that was created for making the Public Administration issue the judges' words to situations that have the same facts and legal issues).

Keywords: Redress, procedure, jurisprudence, victims.

\section{INTRODUCCIÓN}

El conflicto armado interno en Colombia originado en múltiples factores, tales como las limitaciones en la participación política, la inequidad en la distribución de la tierra y la amplia brecha de desigualdad económica, se ha convertido en el enfrentamiento con mayor duración en el mundo ${ }^{1}$. Este ha generado un sinnúmero de consecuencias para el orden del país, desde las perturbaciones a la propiedad, el medio ambiente, la distribución del ingreso y gasto público, hasta los daños psicológicos y socioculturales ocasionados a la población.

El conflicto que ha sufrido la sociedad colombiana en las últimas décadas se ve cuantificado en cifras que revelan la magnitud de los daños causados, siendo un fenómeno que ha generado víctimas que superan los ocho millones de personas registradas a partir de hechos de abandono o despojo forzado de tierras (5.912), actos terroristas, atentados, combates, hostigamientos (98.046), amenaza (374.438), delitos contra la libertad e integridad sexual (24.284), desaparición forzada (168.581), desplazamiento (7.325.975), homicidio (992.851), minas antipersonales, munición sin explotar, artefacto explosivo (11.220), pérdida de bienes muebles o inmuebles (112.437), secuestro (36.443), tortura (10.740) y vinculación de niños, niñas y adolescentes $(8.523)^{2}$. Estas cifras aumentan a diario, aún en el escenario del posconflicto y manifiestan la profunda crisis social que ha enfrentado el país hace más de medio siglo.

A partir de este contexto, han existido varios intentos por finalizar el conflicto y detener el registro de víctimas a partir de acuerdos con diferentes grupos armados como el $\mathrm{M}^{3} 9^{3}$, las Autodefensas Unidas de Colombia (AUC) y la guerrilla de las FARC-EP, generándose con ellos procesos de justicia transicional que pretenden la terminación del conflicto y la consolidación de la paz. La experiencia más próxima a la que actualmente vive el país con las FARC-EP, se identifica en el proceso llevado a cabo con las AUC, a partir del cual se establecieron medidas que permiten facilitar los procesos de paz y la reincorporación a la vida civil de los grupos al margen de la ley ${ }^{4}$, y con la Ley de víctimas, donde se

\footnotetext{
1 Grupo de Memoria Histórica (2013) p. 111.

2 La información de la referencia fue consultada el día 20 de diciembre del 2017 de la Red Nacional de Información -Unidad para las Víctimas-. Registro Único de Víctimas (RUV).

3 Muñoz y Agudelo (2016).

${ }^{4}$ LEY No 975 de 2005.
} 
dictaron medidas para la atención, asistencia y reparación integral a las víctimas del conflicto armado interno 5 .

Esta política pública, que se da desde la perspectiva política o administrativa de la reparación, dispuso en la Ley No 1148 de 2011 la posibilidad de registrarse como víctima para acceder, entre otras medidas de asistencia, a la reparación administrativa durante los dos años siguientes a la ocurrencia del hecho victimizante, si este sucede con posterioridad a su entrada en vigencia, o dentro de los cuatro años siguientes a la promulgación de dicha ley, para quienes hayan sido victimizadas con anterioridad a ese momento ${ }^{6}$.

No obstante, quienes en la actualidad hayan sufrido un hecho dañino con ocurrencia no superior a dos años, no solo cuentan con la posibilidad de acudir a la reparación administrativa, pues la perspectiva judicial de la reparación no ha caducado, razón por la cual pueden acudir al juez contencioso y al proceso de responsabilidad del Estado para reclamar la reparación de los daños causados sobre tales hechos, principalmente a través de los medios de control de naturaleza indemnizatoria y compensatoria (en los medios de control de reparación directa y reparación de los perjuicios causados a un grupo).

Por ejemplo, esta caducidad en el sistema de acciones y responsabilidad propia a los procesos de responsabilidad patrimonial y administrativa del Estado, resulta particularmente relevante frente al derecho a la reparación integral de las víctimas de desplazamiento forzado, cuya magnitud es la más significativa en todo el conflicto y para quienes ese derecho procesal y sustancial ha constituido un auténtico desafío ${ }^{7}$. Lo anterior con fundamento en los siguientes aspectos: i) la duración del proceso judicial, el cual desconoce el plazo razonable; ii) el hecho de que el Estado puede ser declarado irresponsable a pesar de desconocerse contenidos obligacionales de carácter convencional, constitucional y legal a partir de la falla en la prestación del servicio de seguridad y protección; iii) la vigencia de la tesis de la relatividad de las obligaciones del Estado, y iv) la configuración de una aportación de pruebas imposibles a partir de la aplicación de la noción clásica de la carga de la prueba, entre otros.

Por lo anterior, esta investigación pretende establecer la configuración de un derecho procesal transformador para la reparación de las nuevas víctimas del conflicto armado en Colombia, a partir de los desafíos del derecho procesal que se ha venido aplicando en el proceso de responsabilidad del Estado, encontrando como propuesta la aplicabilidad del procedimiento administrativo especial de extensión de la jurisprudencia del Consejo de Estado a terceros por parte de las autoridades, creado recientemente en Colombia en la Ley No 1437 del año 2011. Para lo anterior, se realizará una búsqueda exhaustiva y completa de

\footnotetext{
5 LEY N 1448 de 2011.

6 Al respecto cabe destacar el Proyecto de Ley No 157 de 2015: "Por medio del cual se prorroga el término del artículo 155 de la Ley No 1448 de 2011 - ley de víctimas y de restitución de tierras; ampliando el periodo para que las víctimas presenten ante el Ministerio Público solicitud de inscripción en el registro único de víctimas y se dictan otras disposiciones". Este proyecto fue archivado por tránsito de legislatura el día 21 de junio de 2016, como puede verse en el siguiente link: http://congresovisible.org/proyectos-de-ley/por-medio-del-cualse/7976/\#tab=2. Fecha de consulta: 25 de enero de 2019.

7 En esta investigación se individualiza el hecho dañino del desplazamiento forzado y se enfoca la hipótesis sobre esta población, empleando como criterio de selección que allí se encuentran la mayor cantidad de víctimas del conflicto.
} 
la jurisprudencia del Consejo de Estado (CE) colombiano, único competente en este asunto, desde el periodo 2012 y hasta la actualidad, pero con un límite temporal al año 2017, empleando el criterio de selección sobre aquellas providencias que tratan el asunto en torno a la aplicabilidad de la extensión de la jurisprudencia del Consejo de Estado a terceros, y realizando un análisis en prospectiva de su aplicabilidad al hecho dañino del desplazamiento forzado, pero con proyección a cualquier hecho dañino.

\section{PROBLEMA DE INVESTIGACIÓN}

¿Cómo puede configurarse un derecho procesal transformador para la reparación de las nuevas víctimas del conflicto armado en Colombia, a partir de los desafíos del derecho procesal que se ha venido aplicando en el proceso de responsabilidad del Estado?

\section{ESQUEMA DE RESOLUCIÓN}

El problema jurídico planteado se resolverá en atención al siguiente orden y contenido: i) el ámbito de aplicación de la justicia transicional a las víctimas en Colombia; ii) las nuevas víctimas y la perspectiva política y judicial de la reparación; iii) el proceso de responsabilidad del Estado frente a hechos victimizantes con ocasión del conflicto; iv) derecho procesal transformador: reparación a víctimas desde el procedimiento administrativo especial de extensión de la jurisprudencia del Consejo de Estado a terceros por las autoridades; v) conclusiones; vi) referencias.

\section{EL ÁMBITO DE APLICACIÓN DE LA JUSTICIA TRANSICIONAL A LAS VÍCTIMAS EN COLOMBIA}

Según lo estableció el legislador ${ }^{8}$, se consideran víctimas objeto de su aplicación aquellas personas que individual o colectivamente hayan sufrido un daño por hechos ocurridos a partir del 1 de enero de 1985 (artículo 3), y cuando el daño consista en abandono o despojo forzado de tierras; solo opera respecto de aquellos hechos que hayan sucedido con posterioridad al 1 de enero de 1991 (artículo 75). Asimismo, la Ley No 1448 prevé una vigencia de 10 años contados a partir de su promulgación (10 de junio de 2011) y establece en su artículo 155 que el término para presentar la solicitud de inscripción en el Registro Único de Víctimas (en adelante RUV) es de cuatro años para aquellos hechos victimizantes cuya ocurrencia haya sido con anterioridad a su promulgación ${ }^{9}$, y dos años contados a partir de la ocurrencia del hecho para aquellas víctimas que lo sean con posterioridad a la entrada en vigencia de la mencionada ley. Este registro constituye un presupuesto necesario para acceder a los beneficios contemplados en la Ley de Víctimas ${ }^{10}$.

\footnotetext{
${ }^{8}$ LeY No 1448 de 2011.

9 Tratándose de víctimas de desplazamiento forzado cuyo hecho haya ocurrido con anterioridad a la promulgación de la Ley No 1448 de 2011, esto es, antes del 10 de junio de 2011, contaban con dos años para hacer su declaración (artículo 61), es decir, hasta el 11 de junio de 2013.

${ }_{10}$ Pese a constituir la inscripción en el RUV presupuesto para acceder a la reparación administrativa y demás medidas contempladas en la Ley de Víctimas, existen casos en los que debieron transcurrir más de seis años para obtener el acceso tan solo al reconocimiento como víctima del conflicto armado. SENTENCIA T-417 de 2016; SentenCia T-364 de 2015.
} 
Por su parte, en el Acto Legislativo 1 de 2017, expedido en el marco del Procedimiento Legislativo Especial para la Paz, el ámbito de aplicación de la Jurisdicción Especial para la Paz (JEP) se presenta respecto de aquellas conductas cometidas por causa, con ocasión o en relación directa o indirecta con el conflicto armado, con anterioridad al 1 de diciembre de 2016 (artículo transitorio $5^{\circ}$ ), lo que implica en primer momento que los hechos que ocurran con posterioridad a la mencionada fecha serán de conocimiento de la justicia ordinaria.

Ahora, en cuanto a los demás mecanismos previstos en el Sistema Integral de Verdad, Justicia, Reparación y No Repetición (SIVJRNP), dada la integralidad que se predica del mismo, se entiende que estos estarán dirigidos al mismo ámbito de aplicación de la JEP. No obstante, en el artículo 18 del Acto Legislativo 1 de $2017^{11}$ se establece que, para la reparación que el Sistema Integral otorgará, se tendrá en cuenta "el universo de víctimas del conflicto armado".

Debe considerarse entonces que para el componente de Medidas de Reparación Integral se dará continuidad y fortalecerán los mecanismos existentes y se adoptarán nuevas medidas de reparación ${ }^{12}$, debiendo entenderse que resulta aplicable entonces lo previsto en la Ley No 1448 del año 2011 o Ley de Víctimas y Restitución de Tierras. "De acuerdo con lo anterior, este sistema promoverá procesos de retorno, restitución de tierras, actos tempranos de reconocimiento de la responsabilidad, reparaciones colectivas, rehabilitación psicosocial, participación de las víctimas, entre otros"13.

Así las cosas, las víctimas se encuentran ante dos panoramas, el primero de los cuales se dirige a aquellas personas frente a las cuales ya ha caducado la posibilidad de acceder ante la jurisdicción para obtener la reparación a que tienen derecho desde la perspectiva judicial, y por ello deberán acudir a las medidas de reparación previstas en la Ley No 1448 de 2011, y que serán ampliadas a partir del desarrollo de las Medidas de Reparación que contempla el actual Acuerdo de Paz, es decir, a la perspectiva política o administrativa de la reparación. El segundo, se plantea respecto a aquellas víctimas así consideradas, a partir de un hecho dañino cuya ocurrencia en la actualidad no haya superado los dos años, para las cuales la perspectiva judicial aún sigue vigente a través del ejercicio de los medios de control de reparación directa o reparación de los perjuicios causados a un grupo.

\footnotetext{
11 Sobre el particular, el Instituto de Ciencia Política "Hernán Echavarría Olózaga” señala: "El artículo transitorio 18 del Acto Legislativo 1 de 2017 se queda corto en el reconocimiento del derecho a la reparación material a las víctimas por parte de las FARC, desconociendo lo contemplado en el AFP sobre esta materia. (...) Por lo tanto, la reparación integral a la que hace alusión el precitado artículo, deberá ser interpretada de manera que mejor cobije a las víctimas para garantizar la adecuada protección de sus derechos constitucionales, y de conformidad con los parámetros internacionales aplicables por razón de los compromisos adquiridos por Colombia bajo el derecho internacional”. Instituto de Ciencia Política (2017).

12 Acuerdo final para la terminación del conflicto y la construcción de una paz estable y duradera (2016) pp. 129 y 130.

13 Montoya y Álvarez (2016) p. 11.
} 


\section{LAS NUEVAS VÍCTIMAS Y LA PERSPECTIVA POLÍTICA Y JUDICIAL DE LA REPARACIÓN}

Las personas que han sufrido hechos victimizantes que a la fecha no superen dos años de su ocurrencia, tienen la posibilidad de acceder a dos instrumentos que ofrece el ordenamiento jurídico y el Derecho procesal para obtener la reparación del daño. De un lado se dispone de la perspectiva política de reparación, donde se encuentran las medidas de atención, asistencia y reparación integral creadas en la Ley No 1448 de 2011, desarrolladas en el Decreto 4800 de $2011^{14}$, e incluso las que se originen desde el SIVJRNP, donde tratándose específicamente de acceder a la reparación integral deberán agotar en primer lugar la inscripción en el Registro Único de Víctimas (RUV), para posteriormente adelantar el procedimiento requerido y obtener, entre otras medidas, la indemnización administrativa respecto de la que se prevé en el artículo 149 del Decreto 4800 de 2011, un monto máximo de hasta 40 salarios mínimos legales mensuales vigentes (SMLMV).

Este procedimiento advierte serias deficiencias, fundadas entre otras razones, por la gradualidad $^{15}$ que establece la Ley No 1448 para la implementación de la reparación en el término de su vigencia, no estableciendo un lapso determinado en el que deba hacerse efectiva, lo que implica que la víctima solo recibirá estas medidas hasta tanto exista disponibilidad presupuestal para ello. Esto ha llevado a realidades donde la víctima solicita la reparación por vía administrativa y transcurridos más de cinco años, la administración pública no responde a lo solicitado y aún con mediación de providencia de la Corte Constitucional no se satisface el derecho ${ }^{16}$.

Sin embargo, las víctimas que son objeto de la presente investigación también cuentan con la posibilidad de acceder al aparato jurisdiccional para reclamar la reparación producto del hecho victimizante sufrido, esto dado que para ellas aún no se ha cerrado la perspectiva judicial con miras a obtener una reparación integral derivada de la responsabilidad del Estado - de allí el concepto nuevas víctimas-, objetivo que a partir de las medidas implementadas en la Ley de Víctimas, cuya reparación integral se deriva de la solidaridad del Estado (y que son desarrollo de la perspectiva política de la reparación), no ha sido

\footnotetext{
${ }_{14}$ Estas medidas se dividen en tres clases: i) Medidas de atención y asistencia, en las que se pueden encontrar asistencia en salud, educación, funeraria y ayuda humanitaria; ii) medidas de estabilización económica que contemplan programas y proyectos para la generación de empleo rural y urbano así como el retorno y reubicación de las víctimas de desplazamiento forzado; y iii) medidas de reparación integral, donde se establecen la restitución de vivienda, indemnización por vía administrativa, medidas de satisfacción, rehabilitación y de prevención, protección y garantías de no repetición.

15 "Artículo 18. Gradualidad. El principio de gradualidad implica la responsabilidad Estatal de diseñar herramientas operativas de alcance definido en tiempo, espacio y recursos presupuestales que permitan la escalonada implementación de los programas, planes y proyectos de atención, asistencia y reparación, sin desconocer la obligación de implementarlos en todo el país en un lapso determinado, respetando el principio constitucional de igualdad". LEY N 1448 de 2011.

16 Sentencia T-908 de 2014. Otros casos semejantes puede consultarse: Sentencia T-083 de 2017, y Sentencia T-534 de 2014.
} 
cumplido, produciendo como se expone por estudios especializados "más frustración que beneficios" 17 .

\section{EL PROCESO DE RESPONSABILIDAD DEL ESTADO FRENTE A HECHOS VICTIMIZANTES CON OCASIÓN DEL CONFLICTO}

El proceso de responsabilidad del Estado ${ }^{18}$ en la jurisprudencia del Consejo de Estado por hechos dañinos con ocasión del conflicto posee una caracterización que es propia y particular dependiendo del hecho dañino ${ }^{19}$. Es así como es posible identificar un régimen de responsabilidad si el daño es el desplazamiento forzado, otro si el hecho dañino es el acto terrorista o la desaparición forzada o el secuestro, etc.

Bajo estas particularidades, cada hecho dañino se ubica y desarrolla en uno u otro sistema de responsabilidad, identificándose el sistema objetivo y subjetivo de responsabilidad, y dentro de estos a la falla en la prestación del servicio, ${ }^{20}$ además del daño especial y el riesgo excepcional. Así las cosas, por ejemplo, la responsabilidad del Estado por desplazamiento forzado se estructura a partir de la falla en la prestación del servicio, al tiempo en que la responsabilidad del Estado por actos terroristas se estructura a partir del daño especial o el riesgo excepcional.

Una caracterización particular en este tipo de procesos, a partir de un estudio de casos desde el hecho dañino del desplazamiento forzado, permite establecer cierta caracterización en el objeto de estudio. Tal como se pasa a revelar, al momento de presentarse una demanda desde el proceso judicial tradicional (reparación directa o reparación de los perjuicios causados a un grupo) se concluye lo siguiente:

1. La duración del proceso judicial en ejercicio del medio de control de reparación directa tarda aproximadamente 11,10 años.

2. La duración del proceso judicial en ejercicio del medio de control de reparación de los perjuicios causados a un grupo tarda aproximadamente 4,77 años.

3. No existe un criterio jurisprudencial definitivo respecto a la aplicación de la teoría de la relativización de las obligaciones del Estado, tesis a partir de la cual se construye la irresponsabilidad del Estado.

\footnotetext{
17 Centro Internacional para la Justicia Transicional (2015) p. 1.

18 "El Derecho Administrativo, y de forma particular, la Responsabilidad Extracontractual del Estado, son evidencias palmarias de la creación judicial de reglas jurídicas que son observadas de forma general y resultan vinculantes tanto para las autoridades, como la comunidad en general”. CASALLAS (2012) p. 36.

19 Sobre casos de responsabilidad del Estado por actos terroristas puede consultarse: SENTENCIA 32014 de 2015, proceso en el cual se presentó la demanda el 28 de agosto de 1998, se profirió sentencia de primera instancia el 5 de agosto del 2005 y sentencia de segunda instancia por el CE el 29 de abril del 2015: más de 17 años de proceso judicial. En cuanto a casos de responsabilidad del Estado por homicidio puede consultarse: SENTENCIA 47671 de 2015, proceso en el cual se presentó la demanda el 23 de septiembre del 2010, se profirió sentencia de primera instancia el 13 de febrero del 2013 y sentencia de segunda instancia por el CE el 7 de septiembre del 2015: 5 años de proceso judicial.

$20 \mathrm{Al}$ respecto puede consultarse VIDAL y Molina (2016).
} 
4. No es contundente el criterio jurisprudencial respecto a la aplicación de la teoría de posición de garante en relación con el juicio de causalidad entre el hecho dañino, el contenido obligacional normativamente atribuible y el grado de cumplimiento u observancia por la autoridad y las correspondientes cargas probatorias.

5. Existe claridad en la tipología de perjuicios que desde la jurisprudencia constituyen hechos notorios. Se trata de medios de control que luego de 11,10 ó 4,77 años reconoce exclusivamente tipologías de perjuicios que las subreglas de esta línea han reconocido como hechos notorios, caso del perjuicio moral y por alteración de las condiciones de existencia, los cuales se han reconocido hasta en 100 y 50 SMLMV.

6. No existe claridad en la línea jurisprudencial respecto a los elementos axiológicos o subreglas que se deben observar al momento de pretender la declaratoria de responsabilidad del Estado.

7. En uno de los casos se definió la subregla a partir de la cual “...las actuaciones de los grupos alzados en armas son inciertas, lo cual constituye caso fortuito o fuerza mayor...”, tal como se indicó en el primer caso de la línea jurisprudencial ${ }^{21}$.

8. En uno de los casos se definió la subregla a partir de la cual se estableció la configuración de prueba diabólica en la falla en la prestación del servicio, al indicar en uno de los casos que el demandante “...no demostró que las fuerzas militares contaran con equipo humano y técnico disponible, suficiente en calidad y cantidad para evitar los hechos que dieron lugar al desplazamiento..."22.

Desde esta realidad, la doctrina especializada y en un escenario en el que se comprende lo planteado, ha afirmado que "...el derecho de la responsabilidad extracontractual del Estado en esta materia se presenta como una opción poco adaptada para las víctimas”23.

Naturalmente, la indefinición de reglas de juicio claras y los tiempos excesivamente prolongados del proceso judicial no le responden a la víctima frente a las tragedias generadas con ocasión de estos hechos dañinos, aunado a que en numerosos casos se trata de situaciones sobre sujetos que ostentan una especial protección constitucional y respecto de quienes se debe, bajo criterios de discriminación positiva, crear una garantía judicial que sea consonante con la Convención Americana de Derechos Humanos (artículo 8.1) y la exigencia de los estándares internacionales en materia de derechos humanos en términos de plazo razonable y configuración del juicio de responsabilidad, además de la imperiosa necesidad de criterios jurisprudenciales unificados que definan un derecho sustancial y procesal aplicable en forma clara a través de las subreglas correspondientes desde la jurisprudencia del Consejo de Estado.

\footnotetext{
21 Sentencia AG-062 de 2002. Yáñez (2013 a) p. 168.

22 Sentencia AG-062 de 2002. YáñEz (2013 a) p. 167. Cada uno de estos numerales (1-8) se configuran a partir del estudio de la línea jurisprudencial en las decisiones del Consejo de Estado colombiano, cuyos resultados en ese objeto específico de investigación, fueron publicados en YáNeZ (2013 b). Asímismo, con relación a los numerales 7 y 8 , se enuncian de manera concreta dada la relevancia y gravedad de estas subreglas en el juicio de irresponsabilidad del Estado, siendo estas reglas que deben ser valoradas críticamente al momento en que el Consejo de Estado decida proferir una sentencia de unificación en este asunto.

23 Peláez (2007) p. 301.
} 
Con todo lo anterior, el proceso judicial, desde la perspectiva judicial de la reparación, ha sido un proceso que, en más de 50 años de conflicto cuantificando los demandantes en estos procesos de la línea jurisprudencial de responsabilidad del Estado por desplazamiento forzado (los cuales se resumen a 14 sentencias del Consejo de Estado), ha reparado tan solo a 920 personas. En otros términos, el juez ha reparado al 0,012\% de las víctimas por desplazamiento forzado. Ciertamente el proceso judicial no le ha servido a la víctima.

\section{FIGURA 1}

Cantidad de víctimas del conflicto que han sido reparadas por el Consejo de Estado colombiano a través de los medios de control de reparación directa y reparación de los perjuicios causados a un grupo.

${ }^{*}$ C.P.: Consejero Ponente.

¿Cuántas víctimas han sido reparadas a través del proceso de Responsabilidad del Estado por desplazamiento forzado a través de los medios de control de reparación directa y de grupo?

\begin{tabular}{|l|c|}
\hline \multicolumn{1}{|c|}{ Providencia que declara la responsabilidad del Estado } & Número de Víctimas reparadas \\
\hline (C.P. Correa) (Sentencia 2001-00213-01(AG), de 2006) & 265 \\
\hline (C.P. Correa) (Sentencia 2002-00004-01(AG), de 2007) & 538 \\
\hline (C.P. Fajardo) (Sentencia 2003-00385-01(AG), de 2007) & 82 \\
\hline (C.P. Fajardo) (Sentencia 18436, de 2010) & 3 \\
\hline (C.P. Valle) (Sentencia 23594, de 2012) & 2 \\
\hline (C.P. Rojas) (Sentencia 32274, de 2013) & 4 \\
\hline (C.P. Rojas) (Sentencia 35913, de 2015) & 1 \\
\hline (C.P. Andrade) (Sentencia 34046, de 2015) & 4 \\
\hline (C.P. Santofimio) (Sentencia 50154, de 2015) & 6 \\
\hline (C.P. Santofimio) (Sentencia 48392, de 2015) & 2 \\
\hline (C.P. Santofimio) (Sentencia 40744, de 2016) & 6 \\
\hline (C.P. Andrade) (Sentencia 35029, de 2016) & 3 \\
\hline (C.P. Andrade) (Sentencia 47844, de 2017) & 3 \\
\hline (C.P. Pazos) (Sentencia 41187, de 2017) & 920 \\
\hline Total & 4 \\
\hline
\end{tabular}

Fuente: Los autores.

Este número reducido de víctimas reparadas desde la perspectiva judicial de la reparación obedece, como se indicó, a que el ejercicio de la acción de reparación directa y de grupo se cierra una vez que transcurren dos años a partir de la ocurrencia del hecho dañino, dado que opera la caducidad. Ciertamente, las víctimas desconocían y desconocen estos contenidos jurídicos. Ello, sumado a la dificultad que implica iniciar el proceso judicial y el temor a que pudiesen ser individualizados por sus victimarios en el caso de informar sus casos, llevó a que se extinguiera este plazo. Por esta razón y a partir de la deuda histórica que desde allí se creó, fue que precisamente debió diseñarse la perspectiva política o administra- 
tiva de la reparación, no porque se entienda que el Estado fuese responsable de esos hechos, sino en virtud de la solidaridad y la dignidad humana.

\section{DERECHO PROCESAL TRANSFORMADOR: REPARACIÓN A VÍCTIMAS DESDE EL PROCEDIMIENTO ADMINISTRATIVO ESPECIAL DE EXTENSIÓN DE LA JURISPRUDENCIA DEL CONSEJO DE ESTADO A TERCEROS POR LAS AUTORIDADES}

Indiscutiblemente, la configuración de un derecho procesal transformador en la reparación de las víctimas es imperativo, siendo grandes los desafíos que debe afrontar el derecho procesal que define la responsabilidad del Estado. Ese derecho procesal transformador se configuraría a través del Procedimiento Administrativo Especial de Extensión de la Jurisprudencia del Consejo de Estado (PAEEJCE) ${ }^{24}$, una institución procesal reciente en el ordenamiento jurídico colombiano, creada con la expedición de la Ley No 1437 de 2011 o Código de Procedimiento Administrativo y de lo Contencioso Administrativo (CPACA) ${ }^{25}$.

El objeto del mismo es lograr la aplicación uniforme de la jurisprudencia por parte de las autoridades administrativas a partir de una solicitud presentada por el interesado con fundamento en una sentencia de unificación expedida por el Consejo de Estado; allí se pretende que las consecuencias jurídicas aplicadas en ese caso le sean también aplicables al presente por ser un caso semejante o análogo. Esto constituye un paradigma que en otros términos pretende que las administraciones públicas fundamenten sus decisiones en una jurisprudencia que es obligatoria, pues las autoridades deben resolver la petición presentada teniendo como fundamento lo decidido en casos semejantes por parte del juez administrativo ${ }^{26}$.

Este deber y procedimiento se establece en los artículos 10 y 102 del CPACA, en él la autoridad cuenta con un término de 30 días siguientes a su recepción para resolver la petición incoada, frente a la cual pueden ocurrir tres supuestos: i) que la Administración extienda los efectos de la sentencia de unificación dictada por el Consejo de Estado, ii) la negativa total o parcial por parte de la entidad administrativa, y iii) que la autoridad guarde silencio. Así, en los dos últimos casos el solicitante tiene la posibilidad de acudir ante el Consejo de Estado en los términos previstos en el artículo 269 del referido código, donde "[s]i la solicitud se estima procedente, el Consejo de Estado ordenará la extensión de la ju-

\footnotetext{
24 "Uno de los grandes cimientos de este código tiene precisamente como propósito que la Administración cambie de lógica frente al rol que desempeña frente a los derechos de las personas, en la medida en que comprenda que el juez no es el encargado exclusivo de su protección -quien además debería hacerlo excepcionalmente-, sino que es aquella misma la llamada en primera instancia a abogar por su defensa". AguilerA y Aponte (2017) p. 89. Otros estudios frente al PAEEJCE pueden consultarse en: Daza (2010), y Portilla y Donado (2015).

25 Si bien es cierto, antes de la Ley No 1437 de 2011 existían algunas disposiciones legales y jurisprudenciales que fijaban el seguimiento de las decisiones judiciales por parte de la administración pública, estos no eran considerados vinculantes u obligatorios al momento de ser aplicados en los casos concretos.

${ }^{26}$ Es así como se sostiene que "la fuerza vinculante de los precedentes opera no ya en instancias judiciales -su ámbito de aplicación natural- sino también en sede administrativa”. SANTAELLA (2014) p. 144.
} 
risprudencia y el reconocimiento del derecho a que hubiere lugar. Esta decisión tendrá los mismos efectos del fallo aplicado" 27.

Ahora, tratándose de daños ocasionados en el marco del conflicto armado interno en Colombia frente a los cuales la perspectiva judicial de reparación no ha caducado, y teniendo en cuenta las dificultades a las cuales deben enfrentarse las víctimas para obtener una respuesta del Estado -ya sea en sede de reparación administrativa o a través del proceso de responsabilidad del Estado-, el procedimiento de extensión de la jurisprudencia resulta ser una alternativa viable en atención al desafío que se presenta con las nuevas víctimas del conflicto, pues constituye una nueva realidad sobre la forma de entender y aplicar los pronunciamientos de los jueces, lo que permite el acceso a los derechos de una forma más ágil, la efectividad en la garantía del derecho sustancial porque se requiere de unificación de las subreglas que construyen la ratio decidendi que define la responsabilidad o irresponsabilidad del Estado, evitando con ello la penosa congestión judicial, el gravoso retardo de la sentencia o la excesiva gradualidad de la reparación administrativa prevista en la Ley de Víctimas.

De esta forma, el PAEEJCE se perfila como un mecanismo que sería aplicable a la pretensión de reparación del daño sufrido con ocasión de hechos dañinos propios al conflicto. Sin embargo, dados los requisitos exigidos para la procedencia del procedimiento, se requeriría de una sentencia de unificación frente a cada uno de los hechos dañinos que con ocasión del conflicto generarían responsabilidad del Estado. Bajo este parámetro, realizada una búsqueda exhaustiva y completa sobre los puntos de hecho y de derecho a los que se ha hecho referencia y las sentencias de unificación que han sido proferidas luego de la expedición del $\mathrm{CPACA}^{28}$, se precisa que no existe sentencia de unificación que haga procedente el trámite frente a la reparación del daño ante la administración pública respectiva ${ }^{29}$.

Esta realidad se verifica en el estudio y análisis completo y detallado de la Responsabilidad del Estado por hechos dañinos con ocasión del conflicto armado desde las sentencias de unificación dictadas por el Consejo de Estado a partir de la expedición del Código de Procedimiento Administrativo y de lo Contencioso Administrativo. Evidencia que las sentencias de unificación que han sido proferidas por el Consejo de Estado resuelven pretensiones de asuntos distintos a la responsabilidad del Estado en materia extracontractual. En otros términos, ninguna de ellas afronta una naturaleza del asunto de conformidad a hechos dañinos con ocasión del conflicto armado en Colombia ${ }^{30}$.

\footnotetext{
27 Al respecto puede consultarse: Santaella (2016); Solano (2014); Zambrano (2014); Díaz (2017); Ostau De Lafont (2013); Garzón (2013); Quinche (2016), y Rojas (2010).

28 Con anterioridad a la expedición del Código de Procedimiento Administrativo y de lo Contencioso Administrativo (específicamente para el periodo de búsqueda comprendido entre 1991 y 2012) se profirieron 97 Sentencias de Unificación con fines de extensión, es decir, aquellas que cumplen los criterios establecidos en el artículo 102 del CPACA, esto es, sentencias en las que se haya reconocido un derecho. SALA DE CONSULTA Y Servicio Civil (2014).

29 Los asuntos que pueden llegar a ser objeto de una sentencia de unificación son de competencia exclusiva del CE. En este sentido, corresponde a una potestad discrecional del órgano de cierre de la Jurisdicción Contencioso Administrativa.

${ }^{30}$ Las sentencias de unificación expedidas por el CE que fueron objeto de análisis por los autores a través de la construcción de línea jurisprudencial son las siguientes: SENTENCIA U 24392 (2012); SENTENCIA U 200900030-01 (2012); Sentencia U 24897 (2012); Sentencia U 25022 (2013); Sentencia U 20601 (2013);
} 
Bajo el anterior esquema, se hace imperiosa la necesidad de que el Consejo de Estado unifique sus pronunciamientos jurisprudenciales en torno a la reparación del daño causado a partir de hechos propios al conflicto armado interno, determinando los alcances de las subreglas establecidas en el histórico de su línea jurisprudencial y la interpretación que debe ser aplicada por parte de la administración pública ${ }^{31}$. Esto adquiere especial importancia si se analiza la aplicabilidad que ha tenido el PAEEJCE en su vigencia, del modo como se hace a continuación.

Frente a la actual falta de jurisprudencia de unificación por parte del Consejo de Estado en relación con la reparación integral a que tienen derecho las víctimas del conflicto, se genera la imposibilidad de aplicación del mecanismo procesal en comento, pues desde la vigencia del PAEEJCE no se ha dado aplicación a este frente a la pretensión de extensión de los efectos a terceros a partir de una declaratoria de responsabilidad del Estado ${ }^{32}$.

De esta forma, siendo claro el sentido en el que el Consejo de Estado ha aplicado hasta el momento el mecanismo de extensión jurisprudencial, desde la vigencia del mismo, no es posible en la actualidad que las víctimas puedan acudir a la administración pública para solicitar, con fundamento en una sentencia de unificación, la aplicación de lo dispuesto en aquel fallo a su caso, para obtener la reparación de los perjuicios que resulten del reconocimiento de la responsabilidad del Estado.

Sentencia U 36460 (2013); Sentencia U 2007-00073-01 (2013); Sentencia U 41719 (2013); Sentencia U 48521 (2014); Sentencia U 2013-02192-01 (2014); Sentencia U 2013-00310-01 (2014); Sentencia U 20130007 (2014); Sentencia U 2012-02201-01 (2014); Sentencia U 31170 (2014); Sentencia U 27709 (2014); Sentencia U 28832 (2014); Sentencia U 28804 (2014); Sentencia U 36149 (2014); Sentencia U 31172 (2014); Sentencia U 26251 (2014); Sentencia U 32988 (2014); Sentencia U 1434-14 (2014); Sentencia U 2007-01081-00 (2014); Sentencia U 2013-00015-00 (2014); Sentencia U 37747 (2014); Sentencia U 0775-14 (2015); Sentencia U 2014-00034-00 (2015); Sentencia U 2014-00061-00 (2015); Sentencia U 19146 (2015); Sentencia U 2015-00001-01 (2015); Sentencia U 2014-00066-00 (2015); Sentencia U 224513 (2015); Sentencia U 2006-01002-01 (2015); Sentencia U 18551 (2016); Sentencia U 4683-13 (2016); Sentencia U 3828-14CE-SUj2-001-16 (2016); Sentencia U 0845-15 (2016); Sentencia U 4499-13CESUJ2-002-16 (2016); Sentencia U 2015-00029-00 (2016); Sentencia U 2015-00051-00 (2016); Sentencia U 2013-00701-01 (2016); Sentencia U 2011-00316-00 (2016); Sentencia U 0088-15CE-SUJ2-005-16 (2016); Sentencia U 3420-15CE-SUJ2-003-16 (2016); Sentencia U 0528-14CE-SUJ2-004-16 (2016); Sentencia U 2013-00011-00 (2016); Sentencia U 2686-14 (2016); Sentencia U 2016-00044-00 (2016); Sentencia U 33945B (2017).

31 Ello encuentra respaldo en la siguiente afirmación: “...solo a través del desarrollo y proliferación de las sentencias unificadas la solicitud de extensión de jurisprudencia puede contribuir a que la administración de justicia sea eficiente, ágil y oportuna...”. TAPIERo (2016) p. 165.

32 Esto se evidencia desde el análisis realizado por los autores a los pronunciamientos que se han proferido por el CE respecto de la aplicación del PAEEJCE: Auto 19718 (2013); Auto 46213 (2013); Auto 20093 (2014); Auto 4305-13 (2014); Auto 2449-13 (2014); Sentencia 2062-12 (2014); Auto 3918-13 (2014); Auto 2012-00368-00 (2014); Auto 4209-13 (2014); Auto 4866-14 (2015); Auto 21073 (2015); Auto 51698 (2015); Auto 51861 (2016); Auto 51302 (2016); Sentencia 1669-14 (2016); Auto 55224 (2016); Auto 2015-00252-00 (2016); Auto 2015-00044-00 (2016); Auto 2013-00311-00 (2016); Auto 21961 (2016); Auto 2014-00431- 00 (2016); Auto 2016-00313-00 (2016); Auto 3638-13 (2016); Auto 2449-12 (2016); Auto 2248-12 (2016); Auto 2016-00483-00 (2016); Sentencia 0418-14 (2016); Sentencia 3482-13 (2016); Sentencia 4134-13 (2016); Sentencia 3413-13 (2016); Sentencia 0865-13 (2016); Auto 20893 (2016); Auto 21759 (2016); Auto 21233 (2016); Auto 2015-00254-00 (2017). Sobre este punto puede ser consultado el estudio Sala de Consulta y Servicio Civil (2014) pp. 284-514, donde se hace referencia a la existencia de otras providencias judiciales en las que se resuelven solicitudes de extensión de la jurisprudencia. 
En vigencia de esta propuesta, emitida la sentencia de unificación respecto al hecho dañino específico, por ejemplo, en el desplazamiento forzado, la víctima podría acudir ante la administración pública respectiva -La Nación-Ministerio de Defensa-Ejército NacionalPolicía Nacional- y solicitar la extensión de los efectos, dados los mismos supuestos fácticos y jurídicos. A partir de estos se configuraría un derecho procesal transformador, dado que desde la tutela administrativa efectiva podría otorgarse la reparación integral, sin necesidad de acudir al proceso contencioso administrativo, y alcanzando la máxima instancia de la Jurisdicción Contencioso Administrativa en un tiempo razonable en caso de negación total o parcial en la extensión de los efectos en el caso particular.

Superada esta dificultad, el procedimiento de extensión jurisprudencial podría tenerse como un mecanismo idóneo para aquellas víctimas de hechos antijurídicos sufridos en el contexto del conflicto, que permite que les sea reparado el daño a partir de criterios uniformes fijados por el derecho de los jueces (derecho sustancial) que se proyectan en las decisiones de la administración pública y hacen del derecho procesal un instrumento realmente efectivo frente a un desafío ineludible a la realidad colombiana, en el que la satisfacción de las víctimas no ha sido posible dado que los medios previstos en el ordenamiento jurídico para tal fin, no le responden a la víctima en contraste con la magnitud de su tragedia.

\section{CONCLUSIONES}

El Procedimiento Administrativo Especial de Extensión de la Jurisprudencia del Consejo de Estado es un mecanismo procesal de reciente creación en el ordenamiento jurídico colombiano, con el cual se persigue la aplicación uniforme de la jurisprudencia por parte de la administración pública, ya no como una simple facultad sino como un deber, al extender los efectos de una sentencia de unificación en la que se reconozca un derecho a quienes acrediten los mismos supuestos fácticos y jurídicos. En nuestro criterio, este procedimiento constituye un cambio de paradigma a partir de la tutela administrativa efectiva para quienes hemos denominado las "nuevas víctimas" del conflicto, es decir, aquellas para las cuales no ha operado la caducidad propia de la perspectiva judicial de reparación.

Dado el contexto del conflicto armado en Colombia, el Estado debe propiciar instrumentos que permitan la reparación integral de las víctimas para la cuales aún tienen vigencia las dos perspectivas de reparación (política y judicial). Pero debido a las dificultades que se presentan tanto en la reparación por vía administrativa como en los medios procesales de responsabilidad del Estado, es preciso proponer otras alternativas con las que puedan contar las víctimas, que transformen y que sin necesidad de reformas constitucionales o nuevas leyes, haga posible obtener la reparación del daño en plazos razonables y con subreglas claras y definitivas desde la sentencia de unificación, siendo el procedimiento de extensión jurisprudencial el mecanismo apropiado para responder a este desafío.

Con anterioridad al Código de Procedimiento Administrativo y de lo Contencioso Administrativo (Ley No 1437 de 2011) fueron proferidas 97 sentencias de unificación y desde su entrada en vigencia han sido proferidas aproximadamente 49 sentencias, para un total de 146 sentencias tipo U. En la actualidad, no existe sentencia de unificación que haga procedente el PAEEJCE frente a la reparación del daño ante la administración pública 
respectiva con ocasión de la responsabilidad patrimonial y administrativa del Estado por hechos dañinos con ocasión del conflicto.

Para alcanzar la aplicabilidad del procedimiento, lo cual constituye el que hemos denominado un derecho procesal transformador, el Consejo de Estado debe iniciar una labor de unificación respecto a la responsabilidad del Estado por cada uno de los hechos que con ocasión del conflicto se encuentran relacionados como victimizantes en el Registro Único de Víctimas (RUV): abandono o despojo forzado de tierras, actos terroristas, atentados, combates, hostigamientos, amenaza, delitos contra la libertad e integridad sexual, desaparición forzada, desplazamiento, homicidio, minas antipersonales, munición sin explotar, artefacto explosivo, pérdida de bienes muebles o inmuebles, secuestro, tortura y vinculación de niños, niñas y adolescentes. Con tal propósito, es imperativo que el Consejo de Estado al momento de unificar acuda a la línea jurisprudencial que sobre cada uno de esos hechos dañinos ha tenido en su historia, confirmando las tesis que considere acordes a la Constitución y descartando expresamente aquellas que no puedan ser valoradas para la determinación de la responsabilidad o la posible extensión de los efectos por la administración pública, si se emplea el PAEEJCE por la víctima.

Pese a la dificultad que pueda presentarse para la aplicación del mecanismo de extensión por falta de jurisprudencia de unificación que permita aplicar sus efectos a las reclamaciones por hechos dañinos ocasionados no hace más de dos años, tal limitación puede superarse empleando criterios de priorización en el orden de pronunciamientos del Consejo de Estado, unificando criterios sobre aquellos hechos victimizantes de mayor trascendencia por su magnitud en el conflicto.

La reparación por vía administrativa desde una perspectiva política de la reparación o el proceso judicial en acción de reparación directa o de grupo desde una perspectiva judicial de la reparación, han sido mecanismos que no han otorgado una tutela efectiva al derecho a la reparación integral, no solo por la excesiva duración de los procesos sino por el diferenciable de perjuicios reconocidos en una y otra perspectiva. Para las nuevas víctimas debe existir un derecho procesal transformador, el cual puede configurarse desde el procedimiento administrativo especial de extensión de la jurisprudencia del Consejo de Estado a terceros por las autoridades. Para estos efectos se requiere previa existencia de una sentencia de unificación por cada hecho dañino, donde se considere y motive rigurosamente sobre la línea jurisprudencial vigente a la fecha y se estructure el juicio en forma integral; de esta manera las nuevas víctimas podrían alcanzar la reparación de los perjuicios dentro de los treinta días siguientes a la recepción de la petición especial de extensión por la autoridad respectiva, según los plazos definidos en la Ley, garantizando la tutela administrativa y judicial efectiva, dadas las enormes tragedias de los hechos y el derecho de las víctimas.

En la sentencia de unificación el Consejo de Estado debe definir subreglas relativas a, entre otros: i) el sistema de responsabilidad aplicable, subjetivo u objetivo (la necesidad del conocimiento previo de la autoridad o de la previsibilidad de la ocurrencia del daño), ii) los límites de la tesis de las obligaciones relativas del Estado, iii) la carga de la prueba (estática o dinámica) sobre el daño (suficiencia del registro en el RUV), la relación de causalidad, la tesis de imputación objetiva y posición de garante, iv) las tipologías de perjuicios que podrán ser reconocidos (presunción del daño moral y otros como hecho notorio). De 
esta manera se definiría el derecho sustancial y procesal aplicable, lo cual, adicionalmente, garantiza el principio constitucional de previsibilidad del derecho y de seguridad jurídica.

\section{BIBLIOGRAFÍA CITADA}

Aguilera Martín, Mario y Aponte González, Juan (2017): "La extensión de la jurisprudencia: soportes constitucionales, efectos y aspectos controversiales en su aplicación", Revista Digital de Derecho Administrativo, No 18, julio-diciembre: pp. 85-113.

Casallas Romero, Juan (2012): "Análisis jurisprudencial de las sentencias que declararon la constitucionalidad de las disposiciones de la Ley No 1437 de 2011 con base en las cuales se establece la extensión de la jurisprudencia y una breve reflexión acerca de su relación con la seguridad", Revista Digital de Derecho Administrativo, No 8, juliodiciembre: pp. 27-39.

Centro Internacional para la Justicia Transicional (2015): "Estudio sobre la Implementación del Programa de Reparación Individual en Colombia”. Disponible en: https://www.ictj.org/sites/default/files/ICTJ-COL-Estudio-reparacion-individual-2015. pdf. Fecha de consulta: 25 de enero de 2019.

Daza López, Nubia (2010): "La obligatoriedad del precedente jurisprudencial a la luz de la Ley No 1437 de 2011, teniendo como derrotero el concepto de uniformidad normativa y jurisprudencial”, Revista Iter Ad Veritatem, No 8: pp. 89-103.

Díaz Palacios, Álvaro Andrés (2017): Sentencias de unificación jurisprudencial y mecanismo de extensión (Bogotá D.C., Universidad del Rosario).

Garzón Martínez, Juan Carlos (2013): "La extensión de la jurisprudencia como expresión del principio de legalidad de la actuación administrativa", Revista XXXIV Congreso Colombiano de Derecho Procesal, pp. 525-562.

Grupo de Memoria Histórica (2013): “¡Basta ya! Colombia: memorias de guerra y dignidad”. Disponible en: http://www.centrodememoriahistorica.gov.co/descargas/informes2013/bastaYa/basta-ya-memorias-guerra-dignidad-new-9-agosto.pdf. Fecha de consulta: 25 de enero de 2019.

Instituto de Ciencia Política (2017): "Comentarios al Acto Legislativo 1 de 4 de abril de 2017”. Disponible en: http://www.icpcolombia.org/dev/wp-content/uploads/ 2017/07/17.07.05-OFT-COMENTARIOS-ACTO-LEGISLATIVO-01-DE-2017-JEPA.-MOLANO.pdf. Fecha de consulta: 25 de enero de 2019.

Montoya Restrepo, Nataly y Álvarez Arboleda, Andrés (2016): "Instrumentos de la justicia transicional”, Cuadernos de trabajo en Gobierno y Ciencias Políticas, No 4: pp. 10-13. Disponible en: http://www.eafit.edu.co/escuelas/humanidades/departamento-gobierno-ciencias-politicas/publicaciones/SiteAssets/Paginas/libros/Cuadernos\%20de\%20 Trabajo\%20EAFIT\%20-\%204.pdf. Fecha de consulta: 25 de enero de 2019.

Muñoz Hernández, Luis Antonio y Agudelo Ibáñez, Sirley Juliana (2016): Justicia transicional y sustitución constitucional en Colombia. Caso M-19 (1990) (Medellín, Universidad Libre y Grupo Editorial Diké, primera edición).

Ostau de Lafont Pianeta, Rafael Enrique (2013): "El proceso especial para la extensión de la jurisprudencia”, Revista XXXIV Congreso Colombiano de Derecho Procesal, pp. 505-524. 
Peláez Gutiérrez, Juan Carlos (2007): "Los límites del derecho de la responsabilidad extracontractual del Estado en materia de desplazamiento forzado", en Acosta et al., Cátedra Unesco Derechos Humanos y violencia: Gobierno y gobernanza. El desplazamiento forzado interno en Colombia: Un desafio a los derechos humanos (Bogotá D.C., Universidad Externado de Colombia), pp. 275-302.

Portilla Villamizar, Luz Angela y Donado Restrepo, Javier Alfonso (2015): "La extensión de la jurisprudencia unificada del Consejo de Estado: Nueva competencia de los consultorios jurídicos en materia contencioso administrativa", Revista Ratio Juris, № 20, enerojunio: pp. 267-282.

Quinche Ramírez, Manuel Fernando (2016): El precedente judicial y sus reglas (Bogotá D.C., Ediciones Doctrina y Ley Ltda., segunda edición).

Rojas López, Juan Gabriel (2010): “Comentarios al proyecto de Código de Procedimiento Administrativo y de lo Contencioso Administrativo desde la mirada del Derecho Procesal”, en Ramírez Carvajal et al., Derecho Procesal Contemporáneo (Medellín, Universidad de Medellín), pp. 425-456.

Sala de Consulta y Servicio Civil del Consejo de Estado (2014): "Las sentencias de unificación y el mecanismo de extensión de la jurisprudencia”. Disponible en: http://www.consejodeestado.gov.co/documentos/biblioteca/libros/sentenciasunificacion/ libro.pdf. Fecha de consulta: 25 de enero de 2019.

Santaella Quintero, Hector (2014): "La sujeción de la Administración a los precedentes jurisprudenciales", en Benavides, José Luis (comp.), Contribuciones para el sistema de precedentes jurisprudencial y administrativo (Bogotá D.C., Universidad Externado de Colombia), pp. 141-178.

Santaella Quintero, Hector (2016): Código de Procedimiento Administrativo y de lo Contencioso Administrativo, Ley No 1437 de 2011, comentado y concordado (Bogotá D.C., Universidad Externado de Colombia, segunda edición).

Solano Sierra, Jairo Enrique (2014): Derecho Procesal Contencioso Administrativo (Bogotá D.C., Ediciones Doctrina y Ley Ltda., segunda edición).

Tapiero Rodríguez, Nini Johanna (2016): "Una mirada al ejercicio de la solicitud de extensión de jurisprudencia”, Revista Justicia, № 30, julio-diciembre: pp. 152-168.

Unidad de Víctimas (2017): “Registro Único de Víctimas (RUV)”. Disponible en: https:// rni.unidadvictimas.gov.co/. Fecha de consulta: 20 de diciembre de 2017.

Vidal Perdomo, Jaime y Molina Betancur, Carlos (2016): Derecho Administrativo (Bogotá D.C., Legis Editores S.A., decimocuarta edición).

Yáñez Meza, Diego Armando (2013 a): El derecho de la jurisdicción. Concepciones discutibles y estudio sobre la institución en la vértebra axiológica del juzgar (Cúcuta, Universidad Libre).

Yáñez Meza, Diego Armando (2013 b): "Responsabilidad extracontractual del Estado por desplazamiento forzado de personas", Revista Civilizar. Ciencias Sociales y Humanas, $\mathrm{N}^{\circ}$ 24, enero-junio: pp. 13-46.

YáÑez MeZA, Diego Armando (2014): "La investigación jurídica: necesidad de la ficha de análisis jurisprudencial en el arte del derecho", en Clavijo Cáceres, Darwin et al., 
Método, metodología y técnicas de la investigación aplicadas al derecho (Bogotá D.C., Grupo Editorial Ibáñez \& Universidad de Pamplona), pp. 77-103.

YÁñez Meza, Diego Armando (2015): "La medida cautelar innominada y anticipatoria en el proceso de responsabilidad del Estado por desplazamiento forzado en Colombia", Revista Ius et Praxis, Vol. 21, No 2: pp. 415-438.

Zambrano Cetina, William (2014): "Las estrategias recientes de la jurisdicción colombiana de lo contencioso administrativo para combatir la congestión judicial”, en MonTAÑA Plata, Alberto y Ospina Garzón, Andrés Fernando (edits.), 100 años de la Jurisdicción de lo Contencioso Administrativo "Justificación, retos y aporte al Derecho Administrativo". XIV Jornadas de Derecho Administrativo (Bogotá D.C., Universidad Externado de Colombia), pp. 335-356.

\section{NORMAS CITADAS}

\section{Colombia}

Acto Legislativo $\mathrm{N}^{\circ} 1$ (4/4/2017), Por medio del cual se crea un título de disposiciones transitorias de la Constitución para la terminación del conflicto armado y la construcción de una paz estable y duradera y se dictan otras disposiciones.

ACUERDO FINAL PARA LA TERMINACIÓN DEL CONFLICTO Y LA CONSTRUCCIÓN DE UNA PAZ ESTABLE Y DURADERA (24/11/2016). Disponible en: http://www.altocomisionadoparalapaz.gov. co/procesos-y-conversaciones/Documentos\%20compartidos/24-11-2016NuevoAcuerdoFinal.pdf. Fecha de consulta: 25 de enero de 2019.

Decreto 4800 (20/12/2011), Por el cual se reglamenta la Ley No 1448 de 2011 y se dic$\tan$ otras disposiciones.

LEY No 1448 (10 /6/2011), Por la cual se dictan medidas de atención, asistencia y reparación integral a las víctimas del conflicto armado interno y se dictan otras disposiciones.

LEy No 975 (25/7/ 2005), Por la cual se dictan disposiciones para la reincorporación de miembros de grupos armados organizados al margen de la ley, que contribuyan de manera efectiva a la consecución de la paz nacional y se dictan otras disposiciones para acuerdos humanitarios.

Proyecto de Ley No 157 (17/3/2015), Por medio del cual se prorroga el término del artículo 155 de la Ley No 1448 de 2011.

Ley No 1437 (18/1/2012), Por la cual se expide el Código de Procedimiento Administrativo y de lo Contencioso Administrativo.

\section{JURISPRUDENCIA CITADA}

\section{Colombia}

Auto 19718 (2013): Consejo de Estado Sala de lo Contencioso Administrativo. Sección Cuarta, 1 de febrero de 2013, Radicado No: 2013220-11001-03-27-0002012-00045-00(19718).

Auto 46213 (2013): Consejo de Estado Sala de lo Contencioso Administrativo. Sección Tercera, 4 de abril de 2013, Radicado N: 2015572-11001-03-26-0002013-00019-00(46213). 
Auto 2039-12 (2013): Consejo de Estado Sala de lo Contencioso Administrativo. Sección Segunda. Subsección A, 16 de agosto de 2013, Radicado N: 11001-03-25000-2012-00532-00(2039-12).

Auto 0731-13 (2013): Consejo de Estado Sala de lo Contencioso Administrativo, 11 de septiembre de 2013, Radicado N: 11001-03-25-000-2013-00385-00(0731-13).

Auto 2433-2012 (2013): Consejo de Estado Sala de lo Contencioso Administrativo, 11 de septiembre de 2013, Radicado $\mathrm{N}^{\circ}$ : 2433-2012.

Auto 2059-12 (2013): Consejo de Estado Sala de lo Contencioso Administrativo. Sección Segunda. Subsección A, 11 de septiembre de 2013, Radicado $N^{\circ}$ : 11001-03-25-0002012-00541-00(2059-12).

Auto 20093 (2014): Consejo de Estado Sala de lo Contencioso Administrativo. Sección Cuarta, 15 de enero de 2014, Radicado N: 2017764-11001-03-27000-2013-00017-00(20093).

Auto 2200-2012 (2014): Consejo de Estado Sala de lo Contencioso Administrativo, 20 de enero de 2014, Radicado Nº: 110010325000-201200610-00(2200-2012).

Auto 4305-13 (2014): Consejo de Estado Sala de lo Contencioso Administrativo. Sección Segunda. Subsección A, 29 de enero de 2014, Radicado N: 2075427-11001-03-25000-2013-01673-00(4305-13).

Auto 2694-2012 (2014): Consejo de Estado Sala de lo Contencioso Administrativo, 10 de febrero de 2014, Radicado N: 110010325000-20120088000(2694-2012).

Auto 0189-2013 (2014): Consejo de Estado Sala de lo Contencioso Administrativo, 19 de marzo de 2014, Radicado No: 110010325000-20130008000(0189-2013).

Auto 2449-13 (2014): Consejo de Estado Sala de lo Contencioso Administrativo. Sección Segunda, 31 de marzo de 2014, Radicado Nº 2020197-11001-03-25-0002013-01065-00(2449-13).

Auto 2780-2012 (2014): Consejo de Estado Sala de lo Contencioso Administrativo, 2 de abril de 2014, Radicado N: 110010325000-20120091100(2780-2012).

Auto 3918-13 (2014): Consejo de Estado Sala de lo Contencioso Administrativo. Sección Segunda, 9 de abril de 2014, Radicado N: 2074693-11001-03-25-000-201301528-00(3918-13).

Auto 47833 (2014): Consejo de Estado Sala de lo Contencioso Administrativo. Sección Tercera, 29 de mayo de 2014, Radicado $N^{\circ}$ : 2073686-11001-03-26-0002013-00096-00(47833).

Auto 2012-00368-00 (2014): Consejo de Estado Sala de lo Contencioso Administrativo. Sección Primera, 28 de agosto de 2014, Radicado No: 2073004-11001-03-24-0002012-00368-00.

Auto 4209-13 (2014): Consejo de Estado Sala de lo Contencioso Administrativo. Sección Segunda. Subsección B, 30 de septiembre de 2014, Radicado Nº: 2075834-11001-0325-000-2013-01636-00(4209-13).

Auto 3632-13 (2014): Consejo de Estado Sala de lo Contencioso Administrativo. Sección Segunda. Subsección B, 23 de octubre de 2014, Radicado No: 2075833-11001-0325-000-2013-01437-00(3632-13). 
Auto 4866-14 (2015): Consejo de Estado Sala de lo Contencioso Administrativo. Sección Segunda. Subsección A, 3 de febrero de 2015, Radicado N: 2075700-1100103-25-000-2014-01481-00(4866-14).

Auto 21073 (2015): Consejo de Estado Sala de lo Contencioso Administrativo. Sección Cuarta, 2 de marzo de 2015, Radicado $\mathrm{N}^{\circ}$ : 2075020-1100103-27-000-2014-00026-00-21073.

Auto 51698 (2015): Consejo de Estado Sala de lo Contencioso Administrativo. Sección Tercera, 26 de marzo de 2015, Radicado Nº 2096608-1100103-26-000-2014-00098-00(51698).

Auto 2125-14 (2015): Consejo de Estado Sección Segunda. Subsección A, 22 de abril de 2015, Radicado N: 2076971-11001-03-25-000-2014-00679-00-2125-14.

Auto 52253 (2015): Consejo de Estado Sala de lo Contencioso Administrativo. Sección Tercera. Subsección B, 22 de septiembre de 2015, Radicado N: 2080327-11001-0326-000-2014-01294-00(52253).

Auto 51861 (2016): Consejo de Estado Sala de lo Contencioso Administrativo. Sección Tercera. Subsección A, 21 de enero de 2016, Radicado N: 2080774-1100103-26-000-2014-00112-00(51861).

Auto 51302 (2016): Consejo de Estado Sala de lo Contencioso Administrativo. Sección Tercera. Subsección A, 28 de enero de 2016, Radicado Número: 2078675-1100103-26-000-2014-00074-00(51302).

Auto 55224 (2016): Consejo de Estado Sala de lo Contencioso Administrativo. Sección Tercera. Subsección A, 3 de mayo de 2016, Radicado $N^{\circ}$ : 2089936-11001-03-26-000-2015-00139-00(55224).

Auto 2015-00044-00 (2016): Consejo de Estado Sala de lo Contencioso Administrativo. Sección Primera, 13 de junio de 2016, Radicado $N^{\circ}$ : 2081860-1100103-24-000-2015-00044-00.

Auto 2015-00252-00 (2016): Consejo de Estado Sala de lo Contencioso Administrativo. Sección Primera, 13 de junio de 2016, Radicado N: 2081861-11001-03-24000-2015-00252-00.

Auto 2013-00311-00 (2016): Consejo de Estado Sala de lo Contencioso Administrativo. Sección Primera, 30 de junio de 2016, Radicado N: 243097-11001-03-24000-2013-00311-00.

Auto 21961 (2016): Consejo de Estado Sala de lo Contencioso Administrativo. Sección Cuarta, 8 de agosto de 2016, Radicado N: 2085501-11001-03-27-0002015-00054-00(21961).

Auto 2014-00431- 00 (2016): Consejo de Estado Sala de lo Contencioso Administrativo. Sección Primera, 31 de agosto de 2016, Radicado No: 2084194-11001-03-24-0002014-00431- 00 .

Auto 3638-13 (2016): Consejo de Estado Sala de lo Contencioso Administrativo. Sección Segunda. Subsección B, 12 de septiembre de 2016, Radicado N: 2087889-11001-0325-000-2013-01443-00(3638-13). 
Auto 2016-00313-00 (2016): Consejo de Estado Sala de lo Contencioso Administrativo, 30 de septiembre de 2016, Radicado $N^{\circ}$ : 2085141-11001-0324-000- 2016-00313- 00 .

Auto 2248-12 (2016): Consejo de Estado Sala de lo Contencioso Administrativo. Sección Segunda. Subsección B, 28 de octubre de 2016, Radicado $N^{\circ}$ : 2087882-1100103- 25-000- 2012-00628-00(2248-12).

Auto 2449-12 (2016): Consejo de Estado Sala de lo Contencioso Administrativo, 28 de octubre de 2016, Radicado No: 2087883-11001-03- 25-000- 2012-00727-00(2449-12).

Auto 2016-00483-00 (2016): Consejo de Estado Sala de lo Contencioso Administrativo. Sección Primera, 31 de octubre de 2016, Radicado N: 208574811001-03-24-000-2016-00483-00.

Auto 20893 (2016): Consejo de Estado Sala de lo Contencioso Administrativo, 9 de diciembre de 2016, Radicado $N^{\circ}$ : 2087334-11001-03-25-000- 2013-00929- 00(20893).

Auto 21233 (2016): Consejo de Estado Sala de lo Contencioso Administrativo. Sección Cuarta, 9 de diciembre de 2016, Radicado Nº: 2087332.

Auto 21759 (2016): Consejo de Estado Sala de lo Contencioso Administrativo, 9 de diciembre de 2016, Radicado N: 2087333-11001-03-27-000- 2015-00034- 00(21759).

Auto 2015-00254- 00 (2017): Consejo de Estado Sala de lo Contencioso Administrativo. Sección Primera, 4 de abril de 2017, Radicado Nº: 2096881-1100103- 24-000- 2015-00254- 00.

Sentencia 2001-00213-01(AG) (2006): Consejo de Estado Sala de lo Contencioso Administrativo. Sección Tercera, 26 de enero de 2006, Radicado $N^{\circ}$ : 25000-23-26000-2001-00213-01(AG).

Sentencia 2002-00004-01(AG) (2007): Consejo de Estado Sala de lo Contencioso Administrativo. Sección Tercera, 15 de agosto de 2007, Radicado N: 25000-23-27000-2002-00004-01(AG).

Sentencia 2003-00385-01(AG) (2007): Consejo de Estado Sala de lo Contencioso Administrativo. Sección Tercera, 15 de agosto de 2007, Radicado N: 2067135-1900123-31-000-2003-00385-01(AG).

Sentencia 18436 (2010): Consejo de Estado Sala de lo Contencioso Administrativo. Sección Tercera, 18 de febrero de 2010, Radicado Nº 2001234-2000123-31-000-1998-03713-01-18436.

Sentencia 23594 (2012): Consejo de Estado Sala de lo Contencioso Administrativo. Sección Tercera. Subsección C, 18 de julio de 2012, Radicado N: 2011467-0700123-31-000-2000-00182-01-23594.

Sentencia U 24392 (2012): Consejo de Estado Sala de lo Contencioso Administrativo. Sección Tercera, 23 de agosto de 2012, Radicado N: 2015477-18001-2331-000-1999-00454-01-24392.

Sentencia 2057-12 (2012): Consejo de Estado Sala de lo Contencioso Administrativo, 11 de septiembre de 2012, Radicado $N^{\circ}:$ 2057-12.

Sentencia U 2009-00030-01 (2012): Consejo de Estado Sala Plena de lo Contencioso Administrativo, 11 de septiembre de 2012, Radicado $N^{\circ}$ : 2010859-41001-3331-004-2009-00030-01 APREV. 
Sentencia U 24897 (2012): Consejo de Estado Sala de lo Contencioso Administrativo. Sección Tercera, 19 de noviembre de 2012, Radicado N: 2011870-73001-23-31000-2000-03075-01-24897.

Sentencia 32274 (2013): Consejo de Estado Sala de lo Contencioso Administrativo. Sección Tercera. Subsección B, 3 de mayo de 2013, Radicado N: 2093814-500012315-000-2000-00392-01-32274.

Sentencia U 25022 (2013): Consejo de Estado Sala de lo Contencioso Administrativa. Sección Tercera, 28 de agosto de 2013, Radicado N: 2015567-05001-23-31000-1996-00659-01-25022.

Sentencia U 20601 (2013): Consejo de Estado Sala de lo Contencioso Administrativo. Sección Tercera, 20 de septiembre de 2013, Radicado N: 2018421-41001-23-31000-1994-07654-01-20601.

Sentencia U 36460 (2013): Consejo de Estado Sala de lo Contencioso Administrativo. Sección Tercera, 25 de septiembre de 2013, Radicado $N^{\circ}$ : 2015792-0500123-31-000-2001-00799-01-36460.

Sentencia U 2007-00073-01 (2013): Consejo de Estado Sala Plena de lo Contencioso Administrativo, 8 de octubre de 2013, Radicado $N^{\circ}$ : 2016679-08001-33-31003-2007-00073-01 APREV.

Sentencia U 41719 (2013): Consejo de Estado Sala de lo Contencioso Administrativo. Sección Tercera. Subsección C, 2 de diciembre de 2013, Radicado Nº 2019280-1100103-26-000-2011-00039-00-41719.

Sentencia U 2013-02192-01 (2014): Consejo de Estado Sala de lo Contencioso Administrativo. Sección Quinta, 13 de febrero de 2014, Radicado $N^{\circ}$ : 2018648-0800123-33-000-2013-00310-01 ACU.

Sentencia U 48521 (2014): Consejo de Estado Sala de lo Contencioso Administrativo. Sección Tercera, 13 de febrero de 2014, Radicado N: 2018414-11001-03-26000-2013-00127-00-48521.

Sentencia U 2013-00310-01 (2014): Consejo de Estado Sala de lo Contencioso Administrativo. Sección Quinta, 5 de marzo de 2014, Radicación Nº: 2018648-0800123-33-000-2013-00310-01 ACU.

Sentencia 2062-12 (2014): Consejo de Estado Sala de lo Contencioso Administrativo. Sección Segunda. Subsección B, 26 de marzo de 2014, Radicado Nº: 2018716-1100103-25-000-2012-00544-00(2062-12).

Sentencia 2062-2012 (2014): Consejo de Estado Sala de lo Contencioso Administrativo, 26 de marzo de 2014, Radicado $\mathrm{N}^{\circ}$ : 11001032500-20120054400(2062-2012).

Sentencia U 2013-0007 (2014): Consejo de Estado Sala Plena de lo Contencioso Administrativo, 15 de julio de 2014, Radicado $N^{\circ}$ : 2074092-11001-03-28-000-201300006-00 ACUMULADO 2013-0007 IJ.

Sentencia T-534 (2014): Corte Constitucional Sala Tercera de Revisión, 18 de julio de 2014, Radicado No: T-4.274.338.

Sentencia U 2012-02201-01 (2014): Consejo de Estado Sala Plena de lo Contencioso Administrativo, 5 de agosto de 2014, Radicado N: 2020695-11001-03-15-0002012-02201-01 IJ. 
Sentencia U 26251 (2014): Consejo de Estado Sala de lo Contencioso Administrativo. Sección Tercera, 28 de agosto de 2014, Radicado N: 2020564-66001-23-31-0002001-00731-01-26251.

Sentencia U 27709 (2014): Consejo de Estado Sala de lo Contencioso Administrativa. Sección Tercera, 28 de agosto de 2014, Radicado No: 2020692-73001-23-31-0002001-00418-01-27709.

Sentencia U 28804 (2014): Consejo de Estado Sala de lo Contencioso Administrativo. Sección Tercera, 28 de agosto de 2014, Radicado N: 2020579-23001-23-31-0002001-00278-01-28804

Sentencia U 36149 (2014): Consejo de Estado Sala de lo Contencioso Administrativo. Sección Tercera, 28 de agosto de 2014, Radicado N: 2020578-68001-23-31-0002002-02548-01-36149.

Sentencia U 28832 (2014): Consejo de Estado Sala de lo Contencioso Administrativo. Sección Tercera, 28 de agosto de 2014, Radicado N: 2020691-25000-23-26-0002000-00340-01-28832.

Sentencia U 31170 (2014): Consejo de Estado Sala de lo Contencioso Administrativo. Sección Tercera, 28 de agosto de 2014, Radicado N: 2020695-05001-23-31-0001997-01172-01-31170.

Sentencia U 31172 (2014): Consejo de Estado Sala de lo Contencioso Administrativo. Sección Tercera, 28 de agosto de 2014, Radicado N: 2020577-50001-23-15000-1999-00326-01-31172.

Sentencia U 32988 (2014): Consejo de Estado Sala de lo Contencioso Administrativo. Sección Tercera, 28 de agosto de 2014, Radicado Nº: 2020563-05001-23-25000-1999-01063-01-32988.

Sentencia U 1434-14 (2014): Consejo de Estado Sala de lo Contencioso Administrativo. Sección Segunda, 12 de septiembre de 2014, Radicado N: 2020704-25000-23-42000-2013-00632-01-1434-14.

Sentencia U 2007-01081-00 (2014): Consejo de Estado Sala Plena de lo Contencioso Administrativo, 30 de septiembre de 2014, Radicado N: 2074616-11001-03-15-0002007-01081-00 REV.

Sentencia U 2013-00015-00 (2014): Consejo de Estado Sala Plena de lo Contencioso Administrativo, 11 de noviembre de 2014, Radicado $N^{\circ}$ : 2074093-11001-03-28000-2013-00015-00 IJ.

Sentencia U 37747 (2014): Consejo de Estado Sala de lo Contencioso Administrativo. Sección Tercera, 24 de noviembre de 2014, Radicado N: 2074369-07001-23-31-0002008-00090-01-37747.

Sentencia T-908 (2014): Corte Constitucional Sala Segunda de Revisión, 26 de noviembre de 2014, Radicado $N^{\circ}$ : T-4.452.554

Sentencia U 0775-14 (2015): Consejo de Estado Sala de lo Contencioso Administrativo. Sección Segunda, 22 de enero de 2015, Radicado N: 2073683-25000-23-42-0002012-02017-01-0775-14. 
Sentencia U 2014-00034-00 (2015): Consejo de Estado Sala de lo Contencioso Administrativo. Sección Quinta, 26 de marzo de 2015, Radicado N: 2074061-1100103-28-000-2014-00034-00.

Sentencia T-114 (2015): Corte Constitucional Sala Segunda de Revisión, 26 de marzo de 2015, Radicados $\mathrm{N}^{\circ}:$ T-4. 590.528 y T-4. 591.590.

Sentencia U 2014-00061-00 (2015): Consejo de Estado Sala de lo Contencioso Administrativo. Sección Quinta, 9 de abril de 2015, Radicado $\mathrm{N}^{\circ}$ : 2074060-11001-03-28-000-2014-00061-00.

Sentencia U 19146 (2015): Consejo de Estado Sala de lo Contencioso Administrativo. Sección Tercera. Subsección B, 22 de abril de 2015, Radicado N: 2081810-1500123-31-000-2000-03838-01-19146.

Sentencia 32014 (2015): Consejo de Estado Sala de lo Contencioso Administrativo. Sección Tercera, 29 de abril de 2015, Radicado No: 52001233100019980058001.

Sentencia 35913 (2015): Consejo de Estado Sala de lo Contencioso Administrativo. Sección Tercera, 28 de mayo de 2015, Radicado N: 2090419-52001-23-31-0002003-00625-01-35913.

Sentencia U 2015-00001-01 (2015): Consejo de Estado Sala de lo Contencioso Administrativo. Subsección Primera, 28 de mayo de 2015, Radicado Nº 2075600 11001-03-15-000-2015-00001-01 AC.

Sentencia T-364 (2015): Corte Constitucional Sala Segunda de Revisión, 12 de junio de 2015, Radicado No: T-4. 798.744.

Sentencia T-364 (2015): Corte Constitucional Sala Segunda de Revisión, 12 de junio de 2015, Radicado No: T-4. 798.744.

Sentencia 50154 (2015): Consejo de Estado Sala de lo Contencioso Administrativo. Sección Tercera. Subsección C, 29 de julio de 2015, Radicado N: 2079462-6800123-31-000-2007-00358-01-50154.

Sentencia 34046 (2015): Consejo de Estado Sala de lo Contencioso Administrativo. Sección Tercera. Subsección A, 17 de julio de 2015, Radicado $N^{\circ}$ : 2078116-5000123-31-000-2001-20203-01-34046.

Sentencia 50154 (2015): Consejo de Estado Sala de lo Contencioso Administrativo. Sección Tercera. Subsección C, 29 de julio de 2015, Radicado Nº 2079462-6800123-31-000-2007-00358-01-50154.

Sentencia 48392 (2015): Consejo de Estado Sala de lo Contencioso Administrativo. Sección Tercera. Subsección C, 10 de agosto de 2015, Radicado Nº: 2095348-7600123-31-000-2001-03818-01-48392.

Sentencia 47671 (2015): Consejo de Estado Sala de lo Contencioso Administrativo. Sección Tercera, 7 de septiembre de 2015, Radicado N: 85001-23-31-000-201000178-01 (47671).

Sentencia U 2014-00066-00 (2015): Consejo de Estado Sala de lo Contencioso Administrativo. Sección Quinta, 7 de septiembre de 2015, Radicado N: 207624511001-03-28-000-2014-00066-00. 
Sentencia U 2245-13 (2015): Consejo de Estado Sala de lo Contencioso Administrativo. Sección Segunda, 24 de septiembre de 2015, Radicado N: 2080924-25000-23-42000-2012-00752-01-2245-13.

Sentencia U 2006-01002-01 (2015): Consejo de Estado Sala de lo Contencioso Administrativo. Sección Primera, 11 de diciembre de 2015, Radicado $N^{\circ}$ : 207856925000-23-24-000-2006-01002-01.

Sentencia U 18551 (2016): Consejo de Estado Sala de lo Contencioso Administrativo. Sección Cuarta, 4 de febrero de 2016, Radicado $\mathrm{N}^{\circ}$ : 207759025000-23-27-000-2009-00235-01-18551.

Sentencia U 4683-13 (2016): Consejo de Estado Sala de lo Contencioso Administrativo. Sección Segunda, 25 de febrero de 2016, Radicado N: 207836925000-23-42-000-2013-01541-01-4683-13.

Sentencia 40744 (2016): Consejo de Estado Sala de lo Contencioso Administrativo. Sección Tercera. Subsección C, 14 de marzo de 2016, Radicado N: 50001-23-31000-2002-00094-01-40744.

Sentencia 1669-14 (2016): Consejo de Estado Sala de lo Contencioso Administrativo. Sección Segunda. Subsección A, 14 de abril de 2016, Radicado N: 208081411001-03-25-000-2014-00528-00(1669-14).

Sentencia U 3828-14CE-SUJ2-001-16 (2016): Consejo de Estado Sala de lo Contencioso Administrativo. Sección Segunda, 14 de abril de 2016, Radicado No: 207996615001-33-33-010-2013-00134-01-3828-14CE-SUJ2-001-16.

Sentencia U 0845-15 (2016): Consejo de Estado Sala de lo Contencioso Administrativo. Sección Segunda. Sala de Conjueces, 18 de mayo de 2016, Radicado Nº $2080813-$ 25000-23-25-000-2010-00246-02-0845-15.

Sentencia U 4499-13CE-SUJ2-002-16 (2016): Consejo de Estado Sala de lo Contencioso Administrativo. Sección Segunda, 19 de mayo de 2016, Radicado N: 2084716-0500123-33-000-2012-00791-01-4499-13CE-SUJ2-002-16.

Sentencia U 2015-00029-00 (2016): Consejo de Estado Sala de lo Contencioso Administrativo. Sección Quinta, 25 de mayo de 2016, Radicado N: 2083282-1100103-28-000-2015-00029-00.

Sentencia U 2015-00051-00 (2016): Consejo de Estado Sala de lo Contencioso Administrativo. Sección Quinta, 7 de junio de 2016, Radicación N: 2083274-1100103-28-000-2015-00051-00.

Sentencia 35029 (2016): Consejo de Estado Sala de lo Contencioso Administrativo. Sección Tercera. Subsección A, 14 de julio de 2016, Radicado Nº: 2082660-7300123-31-000-2005-02702-01-35029.

Sentencia U 2013-00701-01 (2016): Consejo de Estado Sala de lo Contencioso Administrativo. Sección Primera, 4 de agosto de 2016, Radicado Nº: 2085911-0500123-33-000-2013-00701-01.

Sentencia U 2011-00316-00 (2016): Consejo de Estado Sala Plena de lo Contencioso Administrativo, 8 de agosto de 2016, Radicado $N^{\circ}$ : 2084664-11001-03-25000-2011-00316-00. 
Sentencia T-417 (2016): Corte Constitucional Sala Sexta de Revisión, 9 de agosto de 2016, Radicado No: T-5. 506.053.

Sentencia U 0088-15CE-SUJ2-005-16 (2016): Consejo de Estado Sala de lo Contencioso Administrativo. Sección Segunda, 25 de agosto de 2016, Radicado N: 208792023001-23-33-000-2013-00260-01-0088-15CE-SUJ2-005-16.

Sentencia U 3420-15CE-SUJ2-003-16 (2016): Consejo de Estado Sala de lo Contencioso Administrativo. Sección Segunda, 25 de agosto de 2016, Radicación Nº $2084027-$ 85001-33-33-002-2013-00060-01-3420-15CE-SUJ2-003-16.

Sentencia U 0528-14CE-SUJ2-004-16 (2016): Consejo de Estado Sala de lo Contencioso Administrativo. Sección Segunda, 25 de agosto de 2016, Radicado Nº 2084699 08001-23-31-000-2011-00628-01-0528-14CE-SUJ2-004-16.

Sentencia U 2013-00011-00 (2016): Consejo de Estado Sala Plena de lo Contencioso Administrativo, 6 de septiembre de 2016, Radicado No: 11001-03-28-000-201300011-00, 11001-03-28-000-2013-00012-00, 11001-03-28-000-2013-00008-00 (Acumulados).

Sentencia U 2013-00011-00 (2016): Consejo de Estado Sala Plena de lo Contencioso Administrativo, 9 de septiembre de 2016, Radicado $N^{\circ}$ : 208466111001-03-28-000-2013-00011-00.

Sentencia 0418-14 (2016): Consejo de Estado Sala de lo Contencioso Administrativo. Sección Segunda. Subsección A, 24 de noviembre de 2016, Radicado Nº 2087891 11001-03-25-000- 2014-00173-00(0418-14).

Sentencia 3413-13 (2016): Consejo de Estado Sala de lo Contencioso Administrativo. Sección Segunda. Subsección A, 24 de noviembre de 2016, Radicado No: 208788811001-03-25-000-2013-01341-00(3413-13).

Sentencia 3482-13 (2016): Consejo de Estado Sala de lo Contencioso Administrativo. Sección Segunda. Subsección A, 24 de noviembre de 2016, Radicado $\mathrm{N}^{\circ}$ : 2087901-11001-03-25-000-2013-01378-00(3482-13).

Sentencia 4134-13 (2016): Consejo de Estado Sala de lo Contencioso Administrativo. Sección Segunda. Subsección A, 24 de noviembre de 2016, Radicado Nº 2087890 11001-03-25-000- 2013-01612-00(4134-13).

Sentencia U 2686-14 (2016): Consejo de Estado Sala de lo Contencioso Administrativo. Sección Segunda, 7 de diciembre de 2016, Radicado Nº $2089277-$ 25000-23-42-000-2013-04676-01-2686-14.

Sentencia U 2016-00044-00 (2016): Consejo de Estado Sala de lo Contencioso Administrativo. Sección Quinta, 12 de diciembre de 2016, Radicado Nº 2087380-1 1001-03-28-000-2016-00044-00.

Sentencia 0865-13 (2016): Consejo de Estado Sala de lo Contencioso Administrativo. Sección Segunda. Subsección A, 12 de diciembre de 2016, Radicado Nº $2087885-$ 11001-03-25-000-2013-00406-00(0865-13).

Sentencia 47844 (2017): Consejo de Estado Sala de lo Contencioso Administrativo. Sección Tercera. Subsección A, 24 de mayo de 2017, Radicado N: 209820550001-23-31-000-2003-00311-02-47844. 
YÁñez MeZa, Diego A. / Jiménez Escalante, Jessica T. —Derecho procesal transformador ..."

Sentencia T-083 (2017): Corte Constitucional Sala Tercera de Revisión, 13 de febrero de 2017, Radicado $\mathrm{N}^{\circ}$ : T-5.711.182.

Sentencia U 33945B (2017): Consejo de Estado Sala Plena de lo Contencioso Administrativo, 27 de junio de 2017, Radicado $N^{\circ}:$ 2100569-50001-23-31-000-2000$3007201-33945 \mathrm{~B}$.

Sentencia 41187 (2017): Consejo de Estado Sala de lo Contencioso Administrativo. Sección Tercera. Subsección B, 31 de agosto de 2017, Radicado N: 13001-23-31000-2001-01492-01-41187. 